\title{
Changes in Skin Surface Temperature after a 10-minute Warm-up on a Bike Ergometer
}

\author{
Michael Fröhlich (Corresponding author) \\ Department of Sport Science, University of Kaiserslautern \\ Erwin Schrödinger Street, 67663 Kaiserslautern, Germany \\ E-mail: michael.froehlich@sowi.uni-kl.de \\ Oliver Ludwig \\ Institute of Sport Sciences, Saarland University \\ Campus B8.1, 66123 Saarbrücken, Germany \\ E-mail: oliver.ludwig1@uni-saarland.de \\ Philip Zeller \\ Institute of Sport Sciences, Saarland University \\ Campus B8.1, 66123 Saarbrücken, Germany \\ E-mail: zellerphilip@icloud.com \\ Hanno Felder \\ Olympic Training Center Rhineland Palatinate/Saarland, \\ Hermann Neuberger Sportschule, 66123 Saarbrücken, Germany \\ E-mail: h.felder@olympiastuetzpunkt.org
}

Received: 09-06- 2015

Accepted: 19-07- 2015

Published: 31-07- 2015

URL: http://dx.doi.org/10.7575/aiac.ijkss.v.3n.3p.13

\begin{abstract}
Introduction: Infrared thermography (IRT) is a non-invasive, non-contact procedure for skin surface temperature (SST) diagnostics and represents an effective, safe, and relatively cost-effective diagnosis tool for estimating the SST. While IRT has been established as a diagnosis tool in numerous medical areas of application, it is still in its initial stages as regards to sports science. We will therefore examine the extent to which IRT can be used for diagnosing the SST after a 10-minute warm-up phase. Method: 20 male sports students $(23.0 \pm 1.6$ years; $75.8 \pm 9.0 \mathrm{~kg} ; 181.0 \pm 6.8 \mathrm{~cm})$ participated in this study. After a standardized preparation phase, the SST of the lower and upper extremities as well as the trunk was determined in a resting state. This was followed by a 10-minute warm-up phase on a bike ergometer set to $1.5 \mathrm{~W} / \mathrm{kg}$ body weight and a cadence of $60-80 \mathrm{rpm}$. After the warm-up, the SST was determined again for the $1 \mathrm{st}$ to 10th minute of the post-strain phase. Results: The 10-minute warm-up resulted in a significant change in the SST over the time of measurement $\left(P<0.05 ; \eta_{\mathrm{p}}^{2}=0.16\right)$. Furthermore, a significant difference of the SST among the different areas of the body was identified $\left(P<0.05 ; \eta_{\mathrm{p}}^{2}=0.15\right)$. The interaction between the time and the area of measurement was also significant $\left(P<0.05 ; \eta_{\mathrm{p}}^{2}=0.16\right)$. The drop in SST from resting state to the first measurement after the 10minute warm-up phase was $1.16^{\circ} \mathrm{C}$ and $3.7 \%$ in the trunk musculature. The temperature of the arm musculature dropped by $0.59^{\circ} \mathrm{C}(1.9 \%)$, while the temperature of the leg musculature decreased by $1.12^{\circ} \mathrm{C}(3.6 \%)$. Ten minutes after the warm-up, the SST of legs and arms was back at the initial state before the strain, but the trunk SST was still $0.74^{\circ} \mathrm{C}$ (2.3\%) lower. Discussion: IRT shows a characteristic SST progression after muscular warm-up. Different SSTs occur depending on the body area, which needs to be considered for standardized warm-ups on the bike ergometer.
\end{abstract}

Keywords: Thermography, warming-up, skin surface temperature, visual imaging, ergometer exercise

\section{Introduction}

Infrared thermography (IRT) is a non-invasive, non-contact tool for skin surface temperature (SST) diagnostics. As IRT is also an effective, safe, and relatively cost-effective diagnosis tool for estimating changes in the SST, IRT can be routinely used to quantify physiological changes and their functions in humans in a resting state and during movement (Hildebrandt, Zeilberger, Ring, and Raschner, 2012). Furthermore, in compliance with measurement standards (Ring and Ammer, 2000; Ring et al., 2007), IRT can provide information on inflammations and tissue overstrain in humans and animals (Turner, 2001). In medical research, especially in cancer diagnostics, i.e., particularly in breast cancer diagnostics, IRT is the diagnosis tool of choice (Buzug, 2011; $\mathrm{Ng}, 2009$ ), and it is also used in rheumatology, dermatology, neurology, and orthopedics (Jiang et al., 2005). In sports medicine, however, IRT has rarely been applied, 
which explains the scientific research demand in this area. Hildebrandt et al. (2012) reason that training and competition are associated with a high degree of stress for the organism, and that early identification of possible overstrains is a central concern of sports medicine. Also, early identification and localization of inflammations and overstrain are a key step in the selection of corresponding treatments.

In addition, the studies by Ferreira et al. (2008), Merla, Mattei, Di Donato, and Romani (2010), Vainer (2005) as well as Zontak, Sideman, Verbitsky, and Beyar (1998) show that IRT can be employed for the diagnosis and description of strain-related SST changes during and after athletic activity.

In all, compared to other application areas, IRT has not been used very often as a diagnosis tool in sports medicine and sports science. Therefore, corresponding findings are only rudimentary, and often confused (Hildebrandt et al., 2012). Since the warm-up phase before athletic activity is said to lead to an increase of body temperature and metabolic rate (Casáis and Martínez, 2012), the following is to examine the extent to which IRT can be used to diagnose the SST changes in the chest region after a 10-minute warm-up, and to estimate the effects of ergometer training on general vs. local muscular warming.

\section{Materials and methods}

\subsection{Sample}

A total of 20 healthy and experienced male students (mean \pm standard deviation; age $23.0 \pm 1.6$ years; range 19-26 years; weight $75.8 \pm 9.0 \mathrm{~kg}$; height $181.0 \pm 6.8 \mathrm{~cm}$; body mass index $23.1 \pm 1.8$ ) participated in this study. All participants were thoroughly informed about the study design as well as the risks and possible benefits associated with the study, and provided written consent prior to participation. The students were familiar with all testing procedures. Participation was voluntary and did not involve any financial compensation. The study complied with ethical guidelines as outlined in the Declaration of Helsinki as well as with ethical standards (Harriss and Atkinson, 2011). All testing sessions were conducted at the Sport Science Institute at the Saarland University.

\subsection{Study procedure}

Starting with a ten-minute acclimatization with naked upper body and sports shorts, the test persons were prepared for the data recording for the initial image (resting phase) of the skin surface temperature (Ring and Ammer, 2000). First, the individual skin areas were defined by means of anatomic reference points using thermally inactive marker points (see figure 1). The test persons had to take an upright standing position that had been previously defined and standardized (Fröhlich, Ludwig, Kraus, and Felder, 2014). The following areas were analyzed: trunk musculature including pectoral and abdominal muscles, arm musculature (left and right forearm muscles and left and right upper arm muscles), and leg musculature (left and right calf muscles and left and right thigh muscles).

After the preparation phase, the 10-minute warm-up phase started on a bike ergometer (Ergo-Fit GmbH and Co KG, Pirmasens, Germany) set to $1.5 \mathrm{~W} / \mathrm{kg}$ body weight and a cadence of 60-80 rounds per minute. The test persons propped their hands and arms only lightly on the handlebar. After the warm-up, the test person resumed their defined standing position for the skin surface temperature analysis. When required, sweat was carefully dabbed off in order to avoid cooling by evaporation. For a duration of ten minutes after strain, the defined skin areas of trunk, arms, and legs were thermographically analyzed in one-minute intervals in an upright standing position (1-10th minute post-strain phase). Room temperature and humidity were controlled and kept constant for the individual persons (Ring and Ammer, 2000). Possible disturbance variables, such as drafts caused by open windows, multiple active persons in the room, heating sources, etc. were eliminated.

\subsection{Measurement methodology}

The thermographic determination of the SST was performed using the infrared thermography system TVS 200 EX (NEC Avio Infrared Technologies Co., Ltd., Tokyo, Japan). The temperature resolution of the camera system was $<0.08^{\circ} \mathrm{C}$ (measurement range from $-20^{\circ} \mathrm{C}$ to $+500^{\circ} \mathrm{C}$, spectral range $8-14 \mu \mathrm{m}$ ). The frame rate was set to $1 / 60$, the effective number of pixels was 320 pixels horizontally and 240 pixels vertically, which is deemed adequate for thermographic diagnostics (Diakides, Diakides, Lupo, Paul, and Balcerak, 2012). The evaluation and processing of thermographic data was performed using the software InfReC Analyzer NS9500 Lite 2.5 (NEC Avio Infrared Technologies Co., Ltd., Tokyo, Japan). The customary used software is a standard tool to calculate mean, minimum, and maximum SST in a defined area by averaging the detected temperature values.

In order to obtain representative measurements of the skin areas, the camera objective was aligned orthogonally to the measured skin areas and calibrated in a uniform way (Lahiri, Bagavathiappan, Jayakumar, and Philip, 2012; Ring and Ammer, 2000). To allow a complete body shot, the distance to the test person was standardized at $3.70 \mathrm{~m}$. The skin measurement areas were standardized via anatomic landmarks that were identified in the thermography image via thermally inactive markers. These markers consisted of cork wafers with a diameter of $15 \mathrm{~mm}$, which were affixed to the body using skin-friendly double-sided adhesive tape. The skin measurement areas were specified individually using the test persons' anthropometrics in percent to the total area (figure 1). 


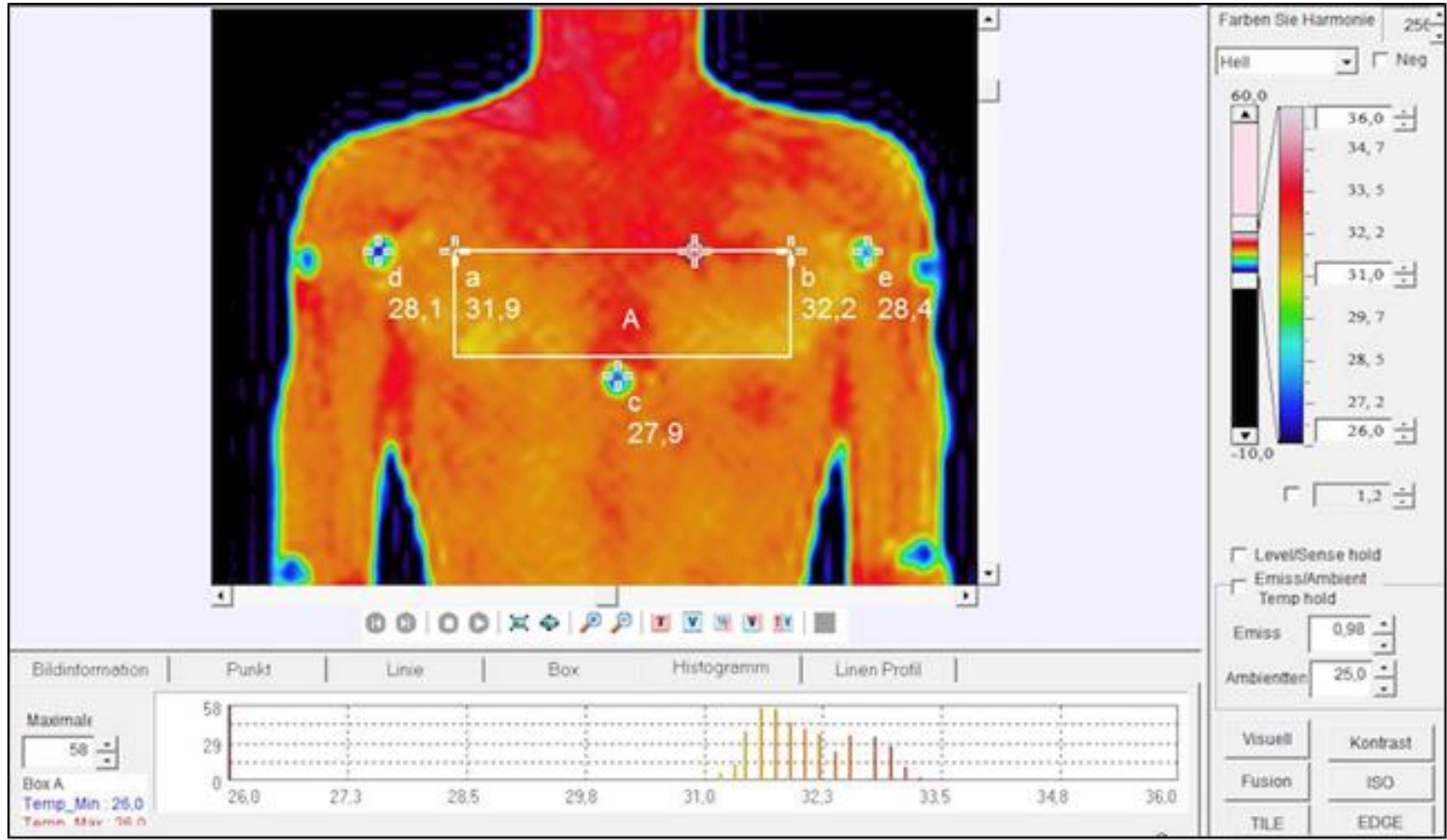

Figure 1. Standardized recording position of the exercise-related skin areas (screenshot of the chest region with M. pectoralis major via InfReC Analyzer NS9500 Lite 2.5 software)

\subsection{Statistical analysis}

The measurement data was calculated using the statistics software IBM SPSS 20 (IBM, New York, USA). In addition to the descriptive values, such as average values, standard deviation, minima, and maxima, 95\% confidence intervals were calculated. To analyze the time course of dependent variables during the exercise intervention, a 2-factor repeatedmeasures analysis of variance (ANOVA: factor time: rest and 1.-10. minute post exercise; factor skin surface area: trunk, arms, and legs) was calculated. Partial eta squared $\left(\eta_{p}^{2}\right)$ was used to assess effect size (ES) with $\eta_{p}^{2}>0.01$, $\eta_{p}^{2}>0.06$, and $\eta_{p}^{2}>0.14$ indicating small, medium, and large effects, respectively (Cohen, 1969). The Levene test was employed to check sphericity, and normal distribution was verified using the Kolmogorov-Smirnov adaptation test. An $\alpha$-level of $P<0.05$ was accepted as statistically significant.

\section{Results}

The ten-minute warming-up on the ergometer resulted in a significant change in the skin surface temperature over the times of measurement $\left(P<0.05 ; \eta_{\mathrm{p}}^{2}=0.16\right)$. A significant difference in the skin surface temperatures of the individual body areas analyzed was identified, as well $\left(P<0.05 ; \eta_{\mathrm{p}}^{2}=0.15\right)$. The interaction of time of measurement and measurement area analyzed was also significant $\left(P<0.05 ; \eta_{\mathrm{p}}^{2}=0.16\right)$. The $95 \%$ confidence intervals of the skin surface temperature were $30.8-31.0^{\circ} \mathrm{C}$ for the trunk musculature, $31.1-31.3^{\circ} \mathrm{C}$ for the arm musculature, and $30.7-30.9^{\circ} \mathrm{C}$ for the leg musculature.

The drop in the skin surface temperature between resting phase and the first measurement after the 10-minute warm-up was $1.2^{\circ} \mathrm{C}$ or $3.7 \%$ for the trunk musculature analyzed. In the arm musculature, the temperature dropped by $0.6^{\circ} \mathrm{C}$ $(1.9 \%)$, and by $1.1^{\circ} \mathrm{C}(3.6 \%)$ in the leg musculature. Ten minutes after the warm-up phase, the skin surface temperature of arms and legs reached the initial level from before the strain, while the trunk's skin surface temperature was still $0.7^{\circ} \mathrm{C}(2.3 \%)$ lower (figure 2$)$.

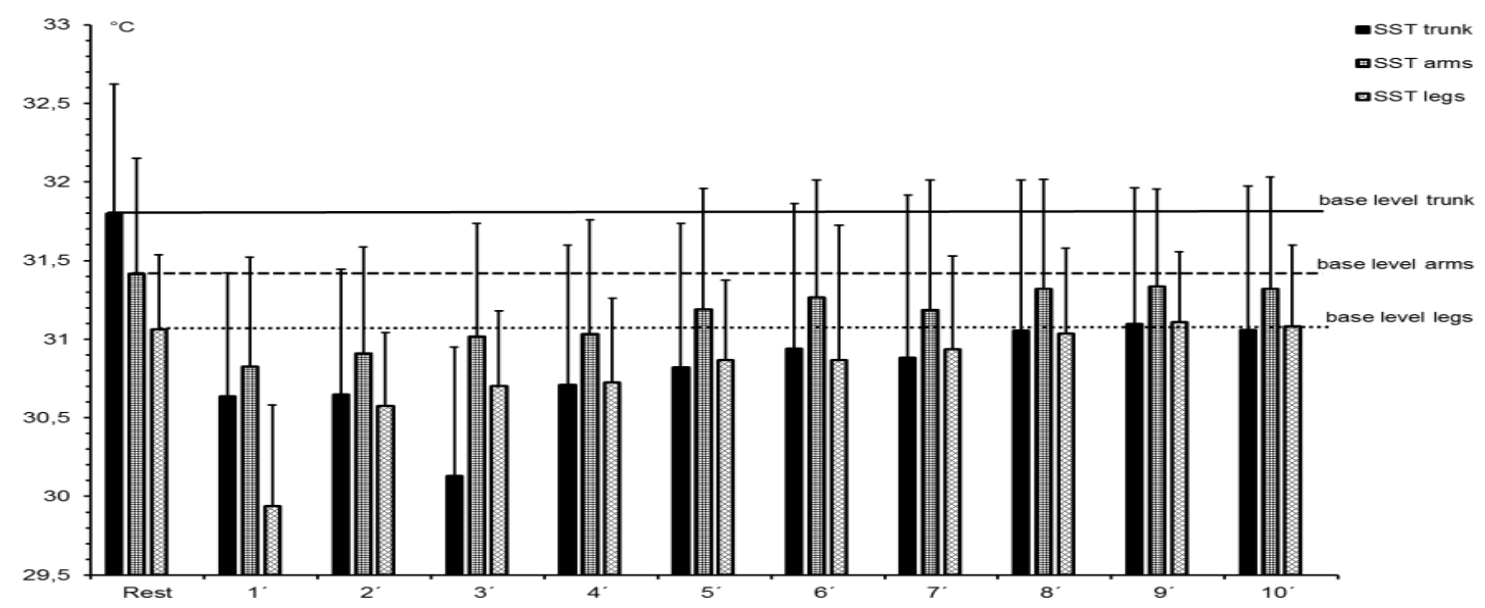

Figure 2. Skin surface temperature curve $\left[{ }^{\circ} \mathrm{C}\right]$ from before strain until 10 minutes after warming-up induced strain 


\section{Discussion}

After a general 10-minute warm-up on the bike ergometer, a specific drop in the skin surface temperature of the directly strained leg musculature and the indirectly strained trunk and arm musculature occurs. This matches the findings of the studies by Torii, Yamasaki, Sasaki, and Nakayama (1992), Wenger (1986), and Zontak et al. (1998) to a large extent. They had also recorded a characteristic progress of the skin surface temperature after various athletic activities. It is noticeable that the skin areas of the leg musculature most strained by the ergometer exercise showed the highest drop in temperature after the strain ended. In addition to vasoconstrictive effects, this is possibly due to evaporation-induced cooling (adiabatic cooling) through perspiration (Wenger, 1986).

It is furthermore important to point out that a warm-up program mainly targeting local muscle strain resulted in thermoregulatory effects in basically all parts of the body. Presumably, the intensive heat production in the large-volume muscle groups of the thigh is responsible for this phenomenon, which might lead to cooling effects in the other parts of the body (Brück, 1986; Wenger, 1986).

The large drop in skin surface temperature of the leg musculature involved can, however, also lead to the conclusion that the local heating effect of the deep muscle tissue due to the specific heating is probably high, as well. Therefore, the benefits of local warm-up procedures for general warm-up within the framework of preparing for an athletic training program should be discussed. Thus, cross trainer or rowing ergometer warm-up programs might be better suited for a general warm-up of multiple muscle groups and/or regions.

While the SST of legs and arms had reached the initial level again 10 minutes after local strain, the SST of the trunk was still $0.7^{\circ} \mathrm{C}$ lower. This could be interpreted as another indication for the blood redistribution in deeper body regions which were not directly strained (De Marées, 2003). Moreover, the results lead to the conclusion that a 10-minute, local warm-up suffices to effect local, strain-induced blood circulation.

The results also serve as proof for the fact that IRT is able to quantitatively and qualitatively determine the primarily used muscle group by analyzing the SST changes occurring during athletic activities (Fröhlich et al., 2014), which is assumed to be applicable for both endurance and strength-specific interventions (Hildebrandt et al., 2012).

In conclusion, thermography provides a non-contact and non-invasive procedure to represent muscle groups used in sports, whose visual imaging capabilities can be applied in sports didactics, as well. While the use of thermography is increasing in medical research (Jiang et al., 2005; Knobel, Guenther, and Rice, 2011; Lahiri et al., 2012; Ring and Ammer, 2012), the research situation in a sports-specific context is still rudimentary (Merla et al., 2010).

\section{Conclusion}

After a 10-minute warm-up on an ergometer, IRT showed a characteristic drop in SST with a subsequent continuous rise of the SST. Using IRT, an indirect redistribution of blood to deeper muscle structures caused by the warm-up has been proven. A 10-minute warm-up seems to be sufficient to bring about local, strain-induced blood circulation. Furthermore, infrared thermography (IRT) is a non-invasive, non-contact procedure for skin surface temperature (SST) diagnostics and represents an effective, safe, and relatively cost-effective diagnosis tool for estimating the SST in sport specific interventions.

\section{Acknowledgement}

The authors sincerely thank the students for participating in the study.

\section{Conflict of interest}

No conflicts of interest exist.

\section{References}

Brïck, K. (1986). Are non-thermal factors important in the cutaneous vascular response to exercise? A proponent's view. The Yale journal of biology and medicine, 59(3), 289-297.

Buzug, T. M. (2011). Infrarot-Bildgebung. In R. Kramme (Hrsg.), Medizintechnik (S. 403-408). Berlin, Heidelberg: Springer.

Casáis, L., and Martínez, M. (2012). Intervention strategies in the prevention of sports injuries from physical activity. In K. R. Zaslav (Hrsg.), An international perspective on topics in sports medicine and sports injury (pp. 355-378). Rijeka: InTech.

Cohen, J. (1969). Statistical power analysis for the behavioral sciences. New York, London: Academic Press.

De Marées, H. (2003). Sportphysiologie. Köln: Sport und Buch Strauß.

Diakides, N. A., Diakides, M., Lupo, J., Paul, J., and Balcerak, R. (2012). Advances in medical infrared imaging: an update. In M. Diakides, J. D. Bronzino \& D. R. Peterson (Hrsg.), Medical infrared imaging: principles and practices (pp. 1.1-1.15). Boca Raton: CRC Press. 
Ferreira, J. A., Mendonça, L. S., Nunes, L. O., Andrade Filho, A. C., Rebelatto, J., and Salvini, T. (2008). Exerciseassociated thermographic changes in young and elderly subjects. Annals of Biomedical Engineering, 36(8), 1420-1427.

Fröhlich, M., Ludwig, O., Kraus, S., and Felder, H. (2014). Changes in skin surface temperature during muscular endurance indicated strain - an explorative study. International Journal of Kinesiology \& Sports Science, 2(3), 23-27.

Harriss, D. J., and Atkinson, G. (2011). Update - Ethical standards in sport and exercise science research. International Journal of Sports Medicine, 32, 819-821.

Hildebrandt, C., Zeilberger, K., Ring, E. F. J., and Raschner, C. (2012). The application of medical infrared thermography in sports medicine. In K. R. Zaslav (Eds.), An international perspective on topics in sports medicine and sports injury (pp. 257-274). Rijeka: InTech.

Jiang, L. J., Ng, E. Y., Yeo, A. C., Wu, S., Pan, F., Yau, W. Y., et al. (2005). A perspective on medical infrared imaging. Journal of Medical Engineering \& Technology, 29(6), 257-267.

Knobel, R. B., Guenther, B. D., and Rice, H. E. (2011). Thermoregulation and thermography in neonatal physiology and disease. Biological Research for Nursing, 13(3), 274-282.

Lahiri, B. B., Bagavathiappan, S., Jayakumar, T., and Philip, J. (2012). Medical applications of infrared thermography: a review. Infrared Physics \& Technology, 55(4), 221-235.

Merla, A., Mattei, P. A., Di Donato, L., and Romani, G. L. (2010). Thermal imaging of cutaneous temperature modifications in runners during graded exercise. Annals of Biomedical Engineering, 38(1), 158-163.

Ng, E. Y. K. (2009). A review of thermography as promising non-invasive detection modality for breast tumor. International Journal of Thermal Sciences, 48(5), 849-859.

Ring, E. F. J., and Ammer, K. (2000). The technique of infra red imaging in medicine. Thermology International, 10(1), 7-14.

Ring, E. F. J., and Ammer, K. (2012). Infrared thermal imaging in medicine. Physiological Measurement, 33(3), R3346.

Ring, E. F. J., Ammer, K., Wiecek, B., Plassmann, P., Jones, C. D., Jung, A., et al. (2007). Quality assurance for thermal imaging systems in medicine. Thermology International, 17(3), 103-106.

Torii, M., Yamasaki, M., Sasaki, M. D., and Nakayama, H. (1992). Fall in skin temperature of exercising man. British Journal of Sports Medicine, 26(1), 29-32.

Turner, T. A. (2001). Diagnostic thermography. Veterinary Clinics of North America Equine Practice, 17(1), 95-113.

Vainer, B. G. (2005). FPA-based infrared thermography as applied to the study of cutaneous perspiration and stimulated vascular response in humans. Physics in Medicine and Biology, 50(23), R63-94.

Wenger, C. B. (1986). Non-thermal factors are important in the control of skin blood flow during exercise only under high physiological strain. The Yale Journal of Biology and Medicine, 59(3), 307-319.

Zontak, A., Sideman, S., Verbitsky, O., and Beyar, R. (1998). Dynamic thermography: analysis of hand temperature during exercise. Annals of Biomedical Engineering, 26(6), 988-993. 